\title{
$F$-closed sets and coupled fixed point theorems without the mixed monotone property
}

\author{
Marwan Amin Kutbi ${ }^{1}$, Antonio Roldán ${ }^{2 *}$, Wutiphol Sintunavarat ${ }^{3 *}$, Juan Martínez-Moreno ${ }^{2}$ and \\ Concepción Roldán ${ }^{4}$
}

${ }^{*}$ Correspondence:

afroldan@ujaen.es; aroldan@ugr.es; wutiphol@mathstat.sci.tu.ac.th

${ }^{2}$ Department of Mathematics, University of Jaén, Campus las Lagunillas s/n, Jaén, 23071, Spain ${ }^{3}$ Department of Mathematics and Statistics, Faculty of Science and Technology, Thammasat University Rangsit Center, Pathumthani, 12121, Thailand

Full list of author information is available at the end of the article

\begin{abstract}
In this paper we present the notion of $F$-closed set (which is weaker than the concept of F-invariant set introduced in Samet and Vetro (Ann. Funct. Anal. 1:46-56, 2010), and we prove some coupled fixed point theorems without the condition of mixed monotone property. Furthermore, we interpret the transitive property as a partial preorder and, then, some results in that paper and in Sintunavarat et al. (Fixed Point Theory Appl. 2012:170, 2012) can be reduced to the unidimensional case.

MSC: 46T99; 47H10;47H09; 54H25
\end{abstract}

Keywords: partially ordered set; fixed point; contractive mapping; mixed monotone property; F-invariant set

\section{Introduction}

One of the very popular tools of a fixed point theory is the Banach contraction principle which first appeared in 1922. It states that if $(X, d)$ is a complete metric space and $T: X \rightarrow X$ is a contraction mapping (i.e., $d(T x, T y) \leq k d(x, y)$ for all $x, y \in X$, where $k$ is a nonnegative number such that $k<1$ ), then $T$ has a unique fixed point. Several mathematicians have been dedicated to improvement and generalization of this principle. In recent times, one of the most attractive research topics in fixed point theory is to prove the existence of a fixed point on metric spaces endowed with partial orders. An initial result in this direction was given by Turinici [1] in 1986. Following this line of research, Ran and Reurings [2] (and, later, Nieto and Rodríguez-López [3]) used a partial order on the ambient metric space to introduce a slightly different contractivity condition, which must be only verified by comparable points. Thus, they reported two versions of the Banach contraction principle in partially ordered sets and applied them to the study of some applications to matrix equations.

Since then, different extensions to coupled, tripled, quadrupled and multidimensional cases have appeared [4-28]. One of the common properties of all these results is the fact that the mapping $F: X^{n} \rightarrow X$ must verify the mixed monotone property. Searching for a generalization of this kind of theorems, Samet and Vetro [29] succeeded in proving some results in which the mapping $F$ did not necessarily have the mixed monotone property. To do that, they introduced the notion of F-invariant set. Later, Sintunavarat, Kumam

๑2013 Kutbi et al: licensee Springer. This is an Open Access article distributed under the terms of the Creative Commons Attribution License (http://creativecommons.org/licenses/by/2.0), which permits unrestricted use, distribution, and reproduction in any medium, provided the original work is properly cited. 
and Cho [30] used this property in order to prove some coupled fixed point theorems for nonlinear contractions without the mixed monotone property.

In this note we observe that the $F$-invariant property introduced in [29] can be interpreted as a partial preorder and, then, some results in that paper and in [30] can be reduced to the unidimensional case.

\section{Preliminaries}

Henceforth, let $X$ be a nonempty set. Given a positive integer $n$, let $X^{n}$ be the product space $X \times X \times \stackrel{n}{ } \times \times X$. We will use $m$ to denote nonnegative integers. Unless otherwise stated, 'for all $m$ ' will mean 'for all $m \geq 0$ '.

Definition 1 (Roldán et al. [31]) A preorder (or a quasiorder) $\preccurlyeq$ on $X$ is a binary relation on $X$ that is reflexive (i.e., $x \preccurlyeq x$ for all $x \in X$ ) and transitive (if $x, y, z \in X$ verify $x \preccurlyeq y$ and $y \preccurlyeq z$, then $x \preccurlyeq z$ ). In such a case, we say that $(X, \preccurlyeq)$ is a preordered space (or a preordered set). If a preorder $\preccurlyeq$ is also antisymmetric ( $x \preccurlyeq y$ and $y \preccurlyeq x$ imply $x=y$ ), then $\preccurlyeq$ is called a partial order.

Throughout this manuscript, let $(X, d)$ be a metric space, and let $\preccurlyeq$ be a preorder (or a partial order) on $X$.

Definition 2 (Roldán [32]) If $(X, \preccurlyeq)$ is a preordered space, a mapping $T: X \rightarrow X$ is $\preccurlyeq$ nondecreasing if $T x \preccurlyeq T y$ for all $x, y \in X$ such that $x \preccurlyeq y$.

In 2003, Ran and Reurings proved the following version of the Banach theorem applicable to metric spaces endowed with a partial order.

Theorem 3 (Ran and Reurings [2]) Let $(X, \preccurlyeq)$ be an ordered set endowed with a metric $d$, and let $T: X \rightarrow X$ be a given mapping. Suppose that the following conditions hold:

(a) $(X, d)$ is complete.

(b) $T$ is $\preccurlyeq$-nondecreasing.

(c) $T$ is continuous.

(d) There exists $x_{0} \in X$ such that $x_{0} \preccurlyeq T x_{0}$.

(e) There exists a constant $k \in(0,1)$ such that $d(T x, T y) \leq k d(x, y)$ for all $x, y \in X$ with $x \succcurlyeq y$.

Then $T$ has a fixed point. Moreover, iffor all $(x, y) \in X^{2}$ there exists $z \in X$ such that $x \preccurlyeq z$ and $y \preccurlyeq z$, we obtain uniqueness of the fixed point.

Later, Nieto and Rodríguez-López slightly modified the hypothesis of the previous result swapping condition (c) by the fact that $(X, d, \preccurlyeq)$ is nondecreasing-regular in the following sense.

Definition 4 We will say that $(X, d, \preccurlyeq)$ is nondecreasing-regular (respectively, nonincreasing-regular) if any $\preccurlyeq$-nondecreasing (respectively, $\preccurlyeq$-nonincreasing) sequence $\left\{x_{m}\right\}$ $d$-converges to $x \in X$, we have that $x_{m} \preccurlyeq x$ (respectively, $x_{m} \succcurlyeq x$ ) for all $m$. And $(X, d, \preccurlyeq)$ is regular if it is both nondecreasing-regular and nonincreasing-regular. 
Inspired by Boyd and Wong's theorem [33], Mukherjea [34] introduced the following kind of control functions:

$$
\Phi=\left\{\varphi:[0, \infty) \rightarrow[0, \infty): \varphi(t)<t \text { and } \lim _{r \rightarrow t^{+}} \varphi(r)<t \text { for each } t>0\right\},
$$

and proved a version of the following result in which the space is not necessarily endowed with a partial order (but the contractivity condition holds over all pairs of points of the space).

Theorem 5 Let $(X, \preccurlyeq)$ be an ordered set endowed with a metric d, and let $T: X \rightarrow X$ be a given mapping. Suppose that the following conditions hold:

(a) $(X, d)$ is complete.

(b) $T$ is $\preccurlyeq$-nondecreasing.

(c) Either $T$ is continuous or $(X, d, \preccurlyeq)$ is nondecreasing-regular.

(d) There exists $x_{0} \in X$ such that $x_{0} \preccurlyeq T x_{0}$.

(e) There exists $\varphi \in \Phi$ such that $d(T x, T y) \leq \varphi(d(x, y))$ for all $x, y \in X$ with $x \succcurlyeq y$.

Then $T$ has a fixed point. Moreover, iffor all $(x, y) \in X^{2}$ there exists $z \in X$ such that $x \preccurlyeq z$ and $y \preccurlyeq z$, we obtain uniqueness of the fixed point.

Some generalizations of the previous result can be found in Wang [35] (to the multidimensional case), in Romaguera [36] (to partial metric spaces, but not necessarily provided with a partial order) and in Roldán [32].

In order to guarantee the existence and uniqueness of a solution of periodic boundary value problems, Gnana Bhaskar and Lakshmikantham (and, subsequently, Lakshmikantham and Ćirić, see [37]) proved, in 2006, existence and uniqueness of a coupled fixed point (a notion introduced by Guo and Lakshmikantham) in the setting of partially ordered metric spaces by introducing the notion of mixed monotone property.

Definition 6 (Guo and Lakshmikantham [38]) We call an element $(x, y) \in X \times X$ a coupled fixed point of the mapping $F: X \times X \rightarrow X$ if

$$
F(x, y)=x \quad \text { and } \quad F(y, x)=y .
$$

In order to ensure the existence of coupled fixed points, Gnana Bhaskar and Lakshmikantham introduced the following condition.

Definition 7 (Gnana Bhaskar and Lakshmikantham [39]) Let $(X, \preccurlyeq)$ be a partially ordered set and $F: X \times X \rightarrow X$. We say that $F$ has the mixed monotone property if $F(x, y)$ is monotone nondecreasing in $x$ and is monotone nonincreasing in $y$, that is, for any $x, y \in X$,

$$
\begin{aligned}
& x_{1}, x_{2} \in X, \quad x_{1} \preccurlyeq x_{2} \quad \Rightarrow \quad F\left(x_{1}, y\right) \preccurlyeq F\left(x_{2}, y\right), \\
& y_{1}, y_{2} \in X, \quad y_{1} \preccurlyeq y_{2} \quad \Rightarrow \quad F\left(x, y_{1}\right) \succcurlyeq F\left(x, y_{2}\right) .
\end{aligned}
$$

Many results were proved to ensure the existence of a coupled fixed point. One of the common properties of all these results is the fact that the mapping $F: X \times X \rightarrow X$ must 
verify the mixed monotone property. Searching for a generalization of this kind of theorems, Samet and Vetro [29] succeeded in proving some results in which the mapping $F$ did not necessarily have the mixed monotone property.

Definition 8 (Samet and Vetro [29]) Let $(X, d)$ be a metric space and $F: X \times X \rightarrow X$ be a given mapping. Let $M$ be a nonempty subset of $X^{4}$. We say that $M$ is an $F$-invariant subset of $X^{4}$ if, for all $x, y, z, w \in X$,

(i) $(x, y, z, w) \in M \Longleftrightarrow(w, z, y, x) \in M$;

(ii) $(x, y, z, w) \in M \Longrightarrow(F(x, y), F(y, x), F(z, w), F(w, z)) \in M$.

The following theorem is the main result in [29].

Theorem 9 (Samet and Vetro [29]) Let $(X, d)$ be a complete metric space, $F: X \times X \rightarrow X$ be a continuous mapping and $M$ be a nonempty subset of $X^{4}$. We assume that

(i) $M$ is F-invariant;

(ii) there exists $\left(x_{0}, y_{0}\right) \in X^{2}$ such that $\left(F\left(x_{0}, y_{0}\right), F\left(y_{0}, x_{0}\right), x_{0}, y_{0}\right) \in M$;

(iii) for all $(x, y, u, v) \in M$, we have

$$
\begin{aligned}
& d(F(x, y), F(u, v)) \\
& \leq \frac{\alpha}{2}[d(x, F(x, y))+d(y, F(y, x))] \\
&+\frac{\beta}{2}[d(u, F(u, v))+d(v, F(v, u))]+\frac{\theta}{2}[d(x, F(u, v))+d(y, F(v, u))] \\
&+\frac{\gamma}{2}[d(u, F(x, y))+d(v, F(y, x))]+\frac{\delta}{2}[d(x, u)+d(y, v)],
\end{aligned}
$$

where $\alpha, \beta, \theta, \gamma, \delta$ are nonnegative constants such that $\alpha+\beta+\theta+\gamma+\delta<1$.

Then $F$ has a coupled fixed point, i.e., there exists $(x, y) \in X \times X$ such that $F(x, y)=x$ and $F(y, x)=y$.

Later, Sintunavarat et al. [30] introduced the notion of transitive property so as to extend the Lakshmikantham and Ćirićs theorem (see [37]).

Definition 10 (Sintunavarat et al. [30]) Let $(X, d)$ be a metric space and $M$ be a subset of $X^{4}$. We say that $M$ satisfies the transitive property if, for all $x, y, z, w, a, b \in X$,

$$
(x, y, z, w) \in M \quad \text { and } \quad(z, w, a, b) \in M \quad \Longrightarrow \quad(x, y, a, b) \in M
$$

Then they proved the following result.

Theorem 11 (Sintunavarat et al. [30]) Let $(X, d)$ be a complete metric space and $M$ be a nonempty subset of $X^{4}$. Assume that there is a function $\varphi:[0, \infty) \rightarrow[0, \infty)$ with $0=$ $\varphi(0)<\varphi(t)<t$ and $\lim _{r \rightarrow t^{+}} \varphi(r)<t$ for each $t>0$, and also suppose that $F: X \times X \rightarrow X$ is a mapping such that

$$
d(F(x, y), F(u, v)) \leq \varphi\left(\frac{d(x, u)+d(y, v)}{2}\right)
$$


(a) F is continuous or

(b) iffor any two sequences $\left\{x_{m}\right\},\left\{y_{m}\right\}$ with $\left(x_{m+1}, y_{m+1}, x_{m}, y_{m}\right) \in M$,

$$
\left\{x_{m}\right\} \rightarrow x, \quad\left\{y_{m}\right\} \rightarrow y,
$$

for all $m \geq 1$, then $\left(x, y, x_{m}, y_{m}\right) \in M$ for all $m \geq 1$.

If there exists $\left(x_{0}, y_{0}\right) \in X \times X$ such that $\left(F\left(x_{0}, y_{0}\right), F\left(y_{0}, x_{0}\right), x_{0}, y_{0}\right) \in M$ and $M$ is an $F$ invariant set which satisfies the transitive property, then there exist $x, y \in X$ such that $x=$ $F(x, y)$ and $y=F(y, x)$, that is, $F$ has a coupled fixed point.

In recent times, it has been proved that many coupled, tripled and quadrupled results can be reduced to the unidimensional case, that is, to Theorems 3 and 5 (see, for instance, Samet et al. [40], Agarwal et al. [41] and Roldán et al. [42]). Furthermore, in some cases, it is not necessary to consider a partial order, but a preorder (see Roldán et al. [31] and Roldán [32]).

In this paper we observe that if $M \subseteq X^{4}$ is $F$-invariant and has the transitive property, we could induce a preorder on $X^{2}$ such that Theorem 11 can be seen as an easy consequence of Theorem 5.

\section{Main results}

In this section we extend some of the previous results using a weaker notion than $F$ invariant set. Throughout this section, let $X$ be a nonempty set, let $F: X \times X \rightarrow X$ be a mapping, and let $M$ be a subset of $X^{4}$.

\subsection{F-closed sets and a related fixed point theorem}

We extend the notion of $F$-invariant set as follows.

Definition 12 We say that $M$ is an F-closed subset of $X^{4}$ if, for all $x, y, u, v \in X$,

$$
(x, y, u, v) \in M \quad \Longrightarrow \quad(F(x, y), F(y, x), F(u, v), F(v, u)) \in M \text {. }
$$

Obviously, every $F$-invariant set is an $F$-closed set. In particular, $\emptyset$ and $X^{4}$ are $F$-closed sets.

Example 13 Let $X=\{0,1\}$, and let $M=\{(0,0,0,0),(1,0,0,0)\} \subseteq X^{4}$. If we consider the mapping $F: X \times X \rightarrow X$ given by $F(x, y)=0$ for all $x, y \in X$, then $M$ is $F$-closed, but it is not $F$-invariant.

In Lemma 18 we will show some nontrivial examples of $F$-closed sets. The following result presents a characterization of $F$-closed sets.

Lemma 14 Let $X$ be a nonempty set, let $F: X \times X \rightarrow X$ be a mapping, and let $M$ be a subset of $X^{4}$. Define:

$$
\begin{aligned}
& (x, y) \sqsubseteq_{M}(u, v) \Longleftrightarrow \quad[(x, y)=(u, v) \text { or }(u, v, x, y) \in M], \quad \text { and } \\
& T_{F}: X^{2} \rightarrow X^{2}, \quad T_{F}(x, y)=(F(x, y), F(y, x)) \quad \text { for all }(x, y) \in X^{2} .
\end{aligned}
$$

Then the following properties hold. 
(1) $\sqsubseteq_{M}$ is reflexive whatever $M$.

(2) $M$ satisfies the transitive property if and only if $\sqsubseteq_{M}$ is a preorder on $X^{2}$.

(3) $M$ is $F$-closed if and only if the mapping $T_{F}$ is $\sqsubseteq_{M}$-nondecreasing.

(4) If $M$ is $F$-invariant, then the mapping $T_{F}$ is $\sqsubseteq_{M}$-nondecreasing.

Proof (1) is obvious. (2) Suppose that $M$ satisfies the transitive property, and let $(x, y) \sqsubseteq_{M}$ $(u, v)$ and $(u, v) \sqsubseteq_{M}(a, b)$. If $(x, y)=(u, v)$ or $(u, v)=(a, b)$, then it is apparent that $(x, y) \sqsubseteq_{M}$ $(a, b)$. In other case, $(u, v, x, y) \in M$ and $(a, b, u, v) \in M$. Since $M$ satisfies the transitive property, then $(a, b, x, y) \in M$, which means that $\complement_{M}$ is a preorder on $X^{2}$. The converse is similar. (3) Suppose that $M$ is $F$-closed. Let $(x, y),(u, v) \in X^{2}$ be such that $(x, y) \sqsubseteq_{M}(u, v)$. If $(x, y)=(u, v)$, then it is clear that $T_{F}(x, y)=T_{F}(u, v)$. Now suppose that $(u, v, x, y) \in M$. Since $M$ is $F$-closed, we know that $(F(u, v), F(v, u), F(x, y), F(y, x)) \in M$, that is, $(F(x, y), F(y, x)) \sqsubseteq_{M}(F(u, v), F(v, u))$, which means that $T_{F}(x, y) \sqsubseteq_{M} T_{F}(u, v)$. Therefore, $T_{F}$ is $\sqsubseteq_{M}$-nondecreasing. The converse is similar. (4) It follows from the fact that $M$ is also F-closed.

Notice that if $d$ is a metric on $X$, then the mapping $D_{d}: X^{2} \times X^{2} \rightarrow[0, \infty)$, defined by

$$
D_{d}((x, y),(u, v))=\frac{d(x, u)+d(y, v)}{2} \text { for all }(x, y),(u, v) \in X^{2} \text {, }
$$

is a metric on $X^{2}$. Furthermore, if $F: X \times X \rightarrow X$ is a $d$-continuous mapping, then $T_{F}$ : $X^{2} \rightarrow X^{2}$, defined as in (2), is $D_{d}$-continuous. Thus, the following result reduces a coupled fixed point theorem to a unidimensional case.

Theorem 15 Theorem 11 follows from Theorem 5.

Proof Let $Y=X \times X=X^{2}$, provided with the metric $D_{d}$ and the preorder $\sqsubseteq_{M}$. It is clear that $\left(Y, D_{d}\right)$ is a complete metric space, and Lemma 14 assures us that $T_{F}$ is $\complement_{M^{-}}$ nondecreasing. The condition $\left(F\left(x_{0}, y_{0}\right), F\left(y_{0}, x_{0}\right), x_{0}, y_{0}\right) \in M$ means that the point $Z_{0}=$ $\left(x_{0}, y_{0}\right)$ verifies $Z_{0} \sqsubseteq_{M} T_{F}\left(Z_{0}\right)$. If $F$ is $d$-continuous, then $T_{F}$ is $D_{d}$-continuous. Taking into account that $\left\{\left(x_{m}, y_{m}\right)\right\} D_{d}$-converges to $(x, y) \in Y$ if and only if $\left\{x_{m}\right\} d$-converges to $x$ and $\left\{y_{m}\right\} d$-converges to $y$, it is clear that condition (b) in Theorem 11 implies that $\left(Y, D_{d}\right.$, $\left.\complement_{M}\right)$ is nondecreasing-regular. Finally, suppose that $(x, y),(u, v) \in Y$ verify $(x, y) \sqsubseteq_{M}(u, v)$ and we are going to show that

$$
D_{d}\left(T_{F}(x, y), T_{F}(u, v)\right) \leq \varphi\left(D_{d}((x, y),(u, v))\right) .
$$

Indeed, if $(x, y)=(u, v)$, there is nothing to prove. Suppose that $(x, y) \neq(u, v)$. In this case, $(u, v, x, y) \in M$. By $(1)$,

$$
d(F(u, v), F(x, y)) \leq \varphi\left(\frac{d(u, x)+d(v, y)}{2}\right)=\varphi\left(D_{d}((x, y),(u, v))\right) .
$$

Moreover, by condition (i) in Definition 8, we have

$$
(u, v, x, y) \in M \quad \Longrightarrow \quad(y, x, v, u) \in M
$$


and using (1) again, it follows that

$$
d(F(y, x), F(v, u)) \leq \varphi\left(\frac{d(y, v)+d(x, u)}{2}\right)=\varphi\left(D_{d}((x, y),(u, v))\right) .
$$

Combining the previous inequalities, we deduce that

$$
\begin{aligned}
D_{d}\left(T_{F}(x, y), T_{F}(u, v)\right) & =D_{d}((F(x, y), F(y, x)),(F(u, v), F(v, u))) \\
& =\frac{d(F(x, y), F(u, v))+d(F(y, x), F(v, u))}{2} \leq \varphi\left(D_{d}((x, y),(u, v))\right) .
\end{aligned}
$$

Using Theorem 5, we conclude that $T_{F}$ has a fixed point, that is, $F$ has a coupled fixed point.

\subsection{Fixed point results without the mixed monotone property}

In the previous result, $M$ is $F$-invariant and satisfies the transitive property. Next we show that these conditions are not necessary in order to prove coupled fixed point theorems. Therefore, we can prove some results avoiding such property.

Theorem 16 Let $(X, d)$ be a complete metric space, let $F: X \times X \rightarrow X$ be a continuous mapping, and let $M$ be a subset of $X^{4}$. Assume that:

(i) $M$ is F-closed;

(ii) there exists $\left(x_{0}, y_{0}\right) \in X^{2}$ such that $\left(F\left(x_{0}, y_{0}\right), F\left(y_{0}, x_{0}\right), x_{0}, y_{0}\right) \in M$;

(iii) there exists $k \in[0,1)$ such that for all $(x, y, u, v) \in M$, we have

$$
d(F(x, y), F(u, v))+d(F(y, x), F(v, u)) \leq k(d(x, u)+d(y, v)) .
$$

Then F has a coupled fixed point.

Proof Using $\left(x_{0}, y_{0}\right) \in X^{2}$ and by recurrence, define $x_{m+1}=F\left(x_{m}, y_{m}\right)$ and $y_{m+1}=F\left(y_{m}, x_{m}\right)$ for all $m \geq 0$. We claim that $\left(x_{m+1}, y_{m+1}, x_{m}, y_{m}\right) \in M$ for all $m \geq 0$. Indeed, $\left(x_{1}, y_{1}, x_{0}, y_{0}\right)=$ $\left(F\left(x_{0}, y_{0}\right), F\left(y_{0}, x_{0}\right), x_{0}, y_{0}\right) \in M$. Assume that $\left(x_{m+1}, y_{m+1}, x_{m}, y_{m}\right) \in M$ for some $m \geq 0$. Since $M$ is $F$-closed,

$$
\begin{aligned}
& \left(x_{m+1}, y_{m+1}, x_{m}, y_{m}\right) \in M \\
& \Rightarrow \quad\left(F\left(x_{m+1}, y_{m+1}\right), F\left(y_{m+1}, x_{m+1}\right), F\left(x_{m}, y_{m}\right), F\left(y_{m}, x_{m}\right)\right) \in M \\
& \Rightarrow \quad\left(x_{m+2}, y_{m+2}, x_{m+1}, y_{m+1}\right) \in M .
\end{aligned}
$$

Applying the contractivity condition to $\left(x_{m+1}, y_{m+1}, x_{m}, y_{m}\right) \in M$, we deduce that, for all $m \geq 0$,

$$
\begin{aligned}
& d\left(F\left(x_{m+1}, y_{m+1}\right), F\left(x_{m}, y_{m}\right)\right)+d\left(F\left(y_{m+1}, x_{m+1}\right), F\left(y_{m}, x_{m}\right)\right) \\
& \quad \leq k\left(d\left(x_{m+1}, x_{m}\right)+d\left(y_{m+1}, y_{m}\right)\right),
\end{aligned}
$$

that is,

$$
d\left(x_{m+2}, x_{m+1}\right)+d\left(y_{m+2}, y_{m+1}\right) \leq k\left(d\left(x_{m+1}, x_{m}\right)+d\left(y_{m+1}, y_{m}\right)\right) \quad \text { for all } m \geq 0 \text {. }
$$


In other words,

$$
\max \left(d\left(x_{m+1}, x_{m}\right), d\left(y_{m+1}, y_{m}\right)\right) \leq d\left(x_{m+1}, x_{m}\right)+d\left(y_{m+1}, y_{m}\right) \leq k^{m}\left(d\left(x_{1}, x_{0}\right)+d\left(y_{1}, y_{0}\right)\right)
$$

for all $m \geq 0$.

This proves that $\left\{x_{m}\right\}$ and $\left\{y_{m}\right\}$ are Cauchy sequences in the complete metric space $(X, d)$. Therefore, there are $x, y \in X$ such that $\left\{x_{m}\right\} \rightarrow x$ and $\left\{y_{m}\right\} \rightarrow y$. Since $F$ is continuous, $\left\{x_{m+1}\right\}=\left\{F\left(x_{m}, y_{m}\right)\right\} \rightarrow F(x, y)$, so $F(x, y)=x$. Analogously, $F(y, x)=y$ and $(x, y)$ is a coupled fixed point of $F$.

Example 17 Let $X=[-1,1]$ provided with the Euclidean metric. Let $M=X^{4} \backslash\{(0,0,0,1)\}$ and consider the mapping $F: X \times X \rightarrow X$ given by $F(x, y)=(x-y) / 4$ for all $x, y \in X$. Then $M$ is an $F$-closed set but it is not an $F$-invariant set. Taking into account that, for all $x, y, u, v \in X$,

$$
|F(x, y)-F(u, v)|+|F(y, x)-F(v, u)|=\frac{1}{2}|(x-u)+(v-y)| \leq \frac{1}{2}(|x-u|+|y-v|),
$$

and choosing $\left(x_{0}, y_{0}\right)=(1,-1)$, we conclude that all hypotheses of Theorem 16 are verified. Then $F$ has a coupled fixed point, which is $(0,0)$, but Theorem 11 cannot be applied because $M$ is not an $F$-invariant set.

The previous theorem also holds using a weaker contractivity condition. To introduce it, we need some notation. Given $(x, y),(u, v) \in X^{2}$, we will use, for simplicity, the notation

$$
\left(T_{F}(x, y), T_{F}(u, v)\right)=(F(x, y), F(y, x), F(u, v), F(v, u)) \in X^{4} .
$$

Given a point $Z_{0}=\left(x_{0}, y_{0}\right) \in X^{2}$, let $T_{F}^{0}\left(Z_{0}\right)=Z_{0}, T_{F}^{1}\left(Z_{0}\right)=T_{F}\left(Z_{0}\right)$ and $T_{F}^{m+1}\left(Z_{0}\right)=$ $T_{F}\left(T_{F}^{m}\left(Z_{0}\right)\right)$ for all $m \geq 0$. We will denote

$$
M_{F}\left(Z_{0}\right)=\left\{\left(T_{F}^{m+1}\left(Z_{0}\right), T_{F}^{m}\left(Z_{0}\right)\right): m \geq 0\right\} \subseteq X^{4} .
$$

Lemma 18 Given $Z_{0} \in X^{2}$, the set $M_{F}\left(Z_{0}\right)$ is F-closed. Indeed, if $M \subseteq X^{4}$ is an F-closed set verifying $\left(T_{F}\left(Z_{0}\right), Z_{0}\right) \in M$, then $M_{F}\left(Z_{0}\right) \subseteq M$.

In particular,

$$
M_{F}\left(Z_{0}\right)=\bigcap\left\{M \subseteq X^{4}: M \text { is } F \text {-closed and }\left(T_{F}\left(Z_{0}\right), Z_{0}\right) \in M\right\} .
$$

Proof Let $Z_{0}=\left(x_{0}, y_{0}\right) \in X^{2}$ and define $x_{m+1}=F\left(x_{m}, y_{m}\right)$ and $y_{m+1}=F\left(y_{m}, x_{m}\right)$ for all $m \geq 0$. Let us prove that $T_{F}^{m}\left(Z_{0}\right)=\left(x_{m}, y_{m}\right)$ for all $m \geq 0$. If $m=0$, it is obvious. If $m=1$, then $\left(x_{1}, y_{1}\right)=\left(F\left(x_{0}, y_{0}\right), F\left(y_{0}, x_{0}\right)\right)=T_{F}\left(x_{0}, y_{0}\right)=T_{F}\left(Z_{0}\right)$. By recurrence,

$$
\left(x_{m+1}, y_{m+1}\right)=\left(F\left(x_{m}, y_{m}\right), F\left(y_{m}, x_{m}\right)\right)=T_{F}\left(x_{m}, y_{m}\right)=T_{F}\left(T_{F}^{m}\left(Z_{0}\right)\right)=T_{F}^{m+1}\left(Z_{0}\right) .
$$


Next we claim that $M_{F}\left(Z_{0}\right)$ is $F$-closed. Let $(x, y, u, v) \in M_{F}\left(Z_{0}\right)$. Then there exists $m \geq 0$ such that $(x, y, u, v)=\left(T_{F}^{m+1}\left(Z_{0}\right), T_{F}^{m}\left(Z_{0}\right)\right)=\left(x_{m+1}, y_{m+1}, x_{m}, y_{m}\right)$. Therefore

$$
\begin{aligned}
& (F(x, y), F(y, x), F(u, v), F(v, u)) \\
& \quad=\left(F\left(x_{m+1}, y_{m+1}\right), F\left(y_{m+1}, x_{m+1}\right), F\left(x_{m}, y_{m}\right), F\left(y_{m}, x_{m}\right)\right) \\
& \quad=\left(x_{m+2}, y_{m+2}, x_{m+1}, y_{m+1}\right)=\left(T_{F}^{m+2}\left(Z_{0}\right), T_{F}^{m+1}\left(Z_{0}\right)\right) \in M_{F}\left(Z_{0}\right) .
\end{aligned}
$$

Finally, let $M \subseteq X^{4}$ be an $F$-closed set verifying $\left(T_{F}\left(Z_{0}\right), Z_{0}\right) \in M$, and we are going to show that $M_{F}\left(Z_{0}\right) \subseteq M$. In particular, we will prove that $\left(T_{F}^{m+1}\left(Z_{0}\right), T_{F}^{m}\left(Z_{0}\right)\right) \in M$ for all $m \geq 0$ by the induction method. Indeed, if $m=0$, by hypothesis, $\left(T_{F}\left(Z_{0}\right), Z_{0}\right) \in M$. Suppose that $\left(T_{F}^{m+1}\left(Z_{0}\right), T_{F}^{m}\left(Z_{0}\right)\right) \in M$ for some $m \geq 0$. Since $M$ is $F$-closed,

$$
\begin{aligned}
& \left(x_{m+1}, y_{m+1}, x_{m}, y_{m}\right)=\left(T_{F}^{m+1}\left(Z_{0}\right), T_{F}^{m}\left(Z_{0}\right)\right) \in M \\
& \quad \Rightarrow \quad\left(F\left(x_{m+1}, y_{m+1}\right), F\left(y_{m+1}, x_{m+1}\right), F\left(x_{m}, y_{m}\right), F\left(y_{m}, x_{m}\right)\right) \in M .
\end{aligned}
$$

Hence,

$$
\begin{aligned}
\left(T_{F}^{m+2}\left(Z_{0}\right), T_{F}^{m+1}\left(Z_{0}\right)\right) & =\left(x_{m+2}, y_{m+2}, x_{m+1}, y_{m+1}\right) \\
& =\left(F\left(x_{m+1}, y_{m+1}\right), F\left(y_{m+1}, x_{m+1}\right), F\left(x_{m}, y_{m}\right), F\left(y_{m}, x_{m}\right)\right) \in M .
\end{aligned}
$$

This completes the induction. Thus, $M_{F}\left(Z_{0}\right) \subseteq M$.

If we particularize Theorem 16 to the $F$-closed set $M=M_{F}\left(Z_{0}\right)$, we obtain the following result.

Corollary 19 Let $(X, d)$ be a complete metric space, let $F: X \times X \rightarrow X$ be a continuous mapping, and suppose that there exist $Z_{0} \in X^{2}$ and $k \in[0,1)$ such that

$$
d(F(x, y), F(u, v))+d(F(y, x), F(v, u)) \leq k(d(x, u)+d(y, v))
$$

for all $(x, y, u, v) \in M_{F}\left(Z_{0}\right)$. Then $F$ has a coupled fixed point.

Notice that in the previous result, we have not necessarily a partial order on $X$ nor a mapping verifying the mixed monotone property.

Theorem 20 Theorem 9 follows from Corollary 19.

Proof Following the proof given in [29], we can consider a constant

$$
k=\frac{\alpha+\beta+\gamma+2 \delta+\theta}{2-(\alpha+\gamma+\beta+\theta)} \in[0,1)
$$

and a sequence $\left\{\left(x_{m+1}, y_{m+1}\right)=\left(F\left(x_{m}, y_{m}\right), F\left(y_{m}, x_{m}\right)\right)\right\}_{m \geq 0}$ such that

$$
d\left(x_{m+2}, x_{m+1}\right)+d\left(y_{m+2}, y_{m+1}\right) \leq k\left(d\left(x_{m+1}, x_{m}\right)+d\left(y_{m+1}, y_{m}\right)\right) \quad \text { for all } m \geq 0,
$$

which is exactly condition (3). Then $F$ has a coupled fixed point. 


\section{Competing interests}

The authors declare that they have no competing interests.

\section{Authors' contributions}

All authors contributed equally and significantly in writing this paper. All authors read and approved the final manuscript.

\section{Author details}

'Department of Mathematics, King Abdulaziz University, P.O. Box 80203, Jeddah, 21589, Saudi Arabia. ${ }^{2}$ Department of Mathematics, University of Jaén, Campus las Lagunillas s/n, Jaén, 23071, Spain. ${ }^{3}$ Department of Mathematics and Statistics, Faculty of Science and Technology, Thammasat University Rangsit Center, Pathumthani, 12121, Thailand. ${ }^{4}$ Department of Statistics and Operations Research, University of Granada, Campus Fuentenueva s/n, Granada, 18071, Spain.

Received: 28 July 2013 Accepted: 6 November 2013 Published: 03 Dec 2013

\section{References}

1. Turinici, M: Abstract comparison principles and multivariable Gronwall-Bellman inequalities. J. Math. Anal. Appl. 117, 100-127 (1986)

2. Ran, ACM, Reurings, MCB: A fixed point theorem in partially ordered sets and some applications to matrix equations. Proc. Am. Math. Soc. 132, 1435-1443 (2004)

3. Nieto, JJ, Rodríguez-López, R: Contractive mapping theorem in partially ordered sets and applications to ordinary differential equations. Order 22, 223-239 (2005)

4. Abbas, M, Khan, MA, Radenović, S: Common coupled fixed point theorem in cone metric space for $w$-compatible mappings. Appl. Math. Comput. 217, 195-202 (2010)

5. Abbas, M, Ali, B, Sintunavarat, W, Kumam, P: Tripled fixed point and tripled coincidence point theorems in intuitionistic fuzzy normed spaces. Fixed Point Theory Appl. 2012, Article ID 187 (2012)

6. Abbas, M, Sintunavarat, W, Kumam, P: Coupled fixed point of generalized contractive mappings on partially ordered G-metric spaces. Fixed Point Theory Appl. 2012, Article ID 31 (2012)

7. Agarwal, RP, Karapinar, E: A note on 'Coupled fixed point theorems for $\alpha-\psi$ contractive type mappings in partially ordered metric spaces'. Fixed Point Theory Appl. 2013, Article ID 216 (2013)

8. Amini-Harandi, A: Coupled and tripled fixed point theory in partially ordered metric spaces with applications to initial value problem. Math. Comput. Model. 57, 2343-2348 (2013)

9. Aydi, H, Abbas, $M$, Sintunavarat, W, Kumam, P: Tripled fixed point of $W$-compatible mappings in abstract metric spaces. Fixed Point Theory Appl. 2012, Article ID 134 (2012)

10. Berinde, V: Generalized coupled fixed point theorems for mixed monotone mappings in partially ordered metric spaces. Nonlinear Anal. 74, 7347-7355 (2011)

11. Chandok, S, Sintunavarat, W, Kumam, P: Some coupled common fixed points for a pair of mappings in partially ordered G-metric spaces. Math. Sci. 7, 24 (2013)

12. Đorić, D, Kadelburg, Z, Radenović, S: Coupled fixed point results for mappings without mixed monotone property. Appl. Math. Lett. 25, 1803-1808 (2012)

13. Golubović, Z, Kadelburg, Z, Radenović, S: Coupled coincidence points of mappings in ordered partial metric spaces. Abstr. Appl. Anal. 2012, Article ID 192581 (2012)

14. Kadelburg, Z, Nashine, HK, Radenović, S: Common coupled fixed point results in partially ordered G-metric spaces. Bull. Math. Anal. Appl. 4, 51-63 (2012)

15. Kadelburg, Z, Nashine, HK, Radenović, S: Some new coupled fixed point results in 0-complete ordered partial metric spaces. J. Adv. Math. Stud. 6, 159-172 (2013)

16. Kadelburg, Z, Radenović, S: Coupled fixed point results under TVS-cone metric and W-cone-distance. Adv. Fixed Point Theory 2, 29-46 (2012)

17. Pant, BD, Chauhan, S, Vujaković, J, Khan, MA, Vetro, C: A coupled fixed point theorem in fuzzy metric space satisfying $\phi$-contractive condition. Adv. Fuzzy Syst. 2013, Article ID 826596 (2013)

18. Karapınar, E: Couple fixed point theorems for nonlinear contractions in cone metric spaces. Comput. Math. Appl. 59(12), 3656-3668 (2010)

19. Karapınar, E, Kumam, P, Sintunavarat, W: Coupled fixed point theorems in cone metric spaces with a c-distance and applications. Fixed Point Theory Appl. 2012, Article ID 194 (2012)

20. Radenović, S: Remarks on some coupled coincidence point result in partially ordered metric spaces. Arab J. Math. Sci. (2013). doi:10.1016/j.j.jmsc.2013.02.003

21. Radenović, S: Remarks on some coupled fixed point results in partial metric spaces. Nonlinear Funct. Anal. Appl. 18, 39-50 (2013)

22. Radenović, S: Remarks on some recent coupled coincidence point results in symmetric G-metric spaces. J. Oper. 2013, Article ID 290525 (2013)

23. Rajić, VĆ, Radenović, S: A note on tripled fixed point of $W$-compatible mappings in tvs-cone metric spaces. Thai J. Math. (2013, in press)

24. Sintunavarat, W, Cho, YJ, Kumam, P: Coupled coincidence point theorems for contractions without commutative condition in intuitionistic fuzzy normed spaces. Fixed Point Theory Appl. 2011, Article ID 81 (2011)

25. Sintunavarat, W, Kumam, P: Coupled coincidence and coupled common fixed point theorems in partially ordered metric spaces. Thai J. Math. 10(3), 551-563 (2012)

26. Roldán, A, Martínez-Moreno, J, Roldán, C: Multidimensional fixed point theorems in partially ordered complete metric spaces. J. Math. Anal. Appl. 396, 536-545 (2012)

27. Roldán, A, Martínez-Moreno, J, Roldán, C: Tripled fixed point theorem in fuzzy metric spaces and applications. Fixed Point Theory Appl. 2013, Article ID 29 (2013)

28. Roldán, A, Martínez-Moreno, J, Roldán, C, Karapınar, E: Meir-Keeler type multidimensional fixed point theorems in partially ordered metric spaces. Abstr. Appl. Anal. 2013, Article ID 406026 (2013) 
29. Samet, B, Vetro, C: Coupled fixed point F-invariant set and fixed point of N-order. Ann. Funct. Anal. 1, 46-56 (2010)

30. Sintunavarat, W, Kumam, P, Cho, YJ: Coupled fixed point theorems for nonlinear contractions without mixed monotone property. Fixed Point Theory Appl. 2012, Article ID 170 (2012)

31. Roldán, A, Karapınar, E: Some multidimensional fixed point theorems on partially preordered $G^{*}$-metric spaces unde $(\psi, \phi)$-contractivity conditions. Fixed Point Theory Appl. 2013, Article ID 158 (2013)

32. Roldán, A: Some coincidence/fixed point theorems under $\Phi$-contractivity conditions without an underlying metric structure and applications (submitted)

33. Boyd, DW, Wong, JSW: On nonlinear contractions. Proc. Am. Math. Soc. 20, 458-464 (1969)

34. Mukherjea, A: Contractions and completely continuous mappings. Nonlinear Anal. 1(3), $235-247$ (1997)

35. Wang, S: Coincidence point theorems for G-isotone mappings in partially ordered metric spaces. Fixed Point Theory Appl. 2013, Article ID 96 (2013)

36. Romaguera, S: Fixed point theorems for generalized contractions on partial metric spaces. Topol. Appl. 159(1), 194-199 (2012)

37. Lakshmikantham, V, Ćirić, LJ: Coupled fixed point theorems for nonlinear contractions in partially ordered metric spaces. Nonlinear Anal. 70(12), 4341-4349 (2009)

38. Guo, D, Lakshmikantham, V: Coupled fixed points of nonlinear operators with applications. Nonlinear Anal. 11, 623-632 (1987)

39. Gnana Bhaskar, T, Lakshmikantham, V: Fixed point theorems in partially ordered metric spaces and applications Nonlinear Anal. 65(7), 1379-1393 (2006)

40. Samet, B, Karapınar, E, Aydi, H, Rajic, C: Discussion on some coupled fixed point theorems. Fixed Point Theory Appl. 2013, Article ID 50 (2013)

41. Agarwal, R, Karapınar, E: Remarks on some coupled fixed point theorems in G-metric spaces. Fixed Point Theory Appl. 2013, Article ID 2 (2013)

42. Roldán, A, Martínez-Moreno, J, Roldán, C, Karapınar, E: Some remarks on multidimensional fixed point theorems. Fixed Point Theory (accepted for publication)

10.1186/1687-1812-2013-330

Cite this article as: Kutbi et al.: F-closed sets and coupled fixed point theorems without the mixed monotone property. Fixed Point Theory and Applications 2013, 2013:330

\section{Submit your manuscript to a SpringerOpen ${ }^{\odot}$ journal and benefit from:}

- Convenient online submission

- Rigorous peer review

Immediate publication on acceptance

- Open access: articles freely available online

- High visibility within the field

- Retaining the copyright to your article 